\title{
The Modulatory Effect of Dietary Apostichopus japonicus on Mice with Ulcerative Colitis Induced by Trinitrobenzene Sulfonic Acid
}

\author{
Hongjie Shi' ${ }^{1}$, Hong Sun ${ }^{2}$, Rong Zheng ${ }^{1}$, Shangyun Lu${ }^{1}$, Fang Liu ${ }^{1}$, Na Zhang1, Changhu Xue1, \\ Qingjuan Tang1*
}

${ }^{1}$ College of Food Science and Engineering, Ocean University of China, Qingdao, China

${ }^{2}$ Emergency Medicine, Shandong Jining No. 2 Peoples Hospital, Jining, China

Email: ^tangqingjuan@ouc.edu.cn

How to cite this paper: Shi, H.J., Sun, H., Zheng, R., Lu, S.Y., Liu, F., Zhang, N., Xue, C.H. and Tang, Q.J. (2016) The Modulatory Effect of Dietary Apostichopus japonicus on Mice with Ulcerative Colitis Induced by Trinitrobenzene Sulfonic Acid. Journal of Biosciences and Medicines, 4, 15-27.

http://dx.doi.org/10.4236/jbm.2016.410003

Received: September 5, 2016

Accepted: October 11, 2016

Published: October 14, 2016

Copyright $\odot 2016$ by authors and Scientific Research Publishing Inc. This work is licensed under the Creative Commons Attribution International License (CC BY 4.0).

http://creativecommons.org/licenses/by/4.0/

\section{(c) (i) Open Access}

\begin{abstract}
Sea cucumber is a food with nutritional benefits distributing mainly in Asia, and Apostichopus japonicus ( $A$. japonicus) is a kind of sea cucumber whose quality is better than any others. However, different processing methods make various effect on its quality. In this study, we evaluated the protection effect of $A$. japonicus with different processing methods on mice with ulcerative colitis induced by trinitrobenzene sulfonic acid (TNBS), especially on the intestinal microflora. The expression of IFN- $\gamma /$ IL- 4 and IL- $1 \beta$ in gut, and intestinal microbiota were discussed. The results revealed that three different processing methods of $A$. japonicus could decrease the expression of inflammatory cytokines, except for the expression of IFN- $\gamma / \mathrm{IL}-4$ treated with enzymatic, and dried $A$. japonicus was the most efficient. A. japonicus could change the microbiotic imblance relatively back to normal in terms of bacterial diversity and composition, meanwhile increase the abundance of Bifidobacteria, Lactobacillus and Clostridium leptum. The elements of protein, polysaccharide in dried, instant, enzymatic $A$. japonicus are $73.09 \%, 65.06 \%, 57.42 \%$ and $6.72 \%, 5.46 \%, 5.45 \%$ respectively. This study indicated that $A$. japonicus have a good improving effect on ulcerative colitis, especially on the microbiome, and processing methods had an effect on alleviation of ulcerative colitis, which might be associated with content of protein and polysaccharide.
\end{abstract}

\section{Keywords}

Apostichopus japonicus, Ulcerative Colitis, Trinitrobenzene Sulfonic Acid, Intestinal Microbiota 


\section{Introduction}

Ulcerative colitis (UC) and Crohn's disease are two major forms of inflammatory bowel disease. UC can lead to disorder of the colonic mucosa in some area and finally extends to the entire colon [1]. As a common drug, trinitrobenzene sulfonic acid (TNBS) is widely used to induce colitis in mice model [2]. Studies have suggested that UC results from growth production of cytokines, such as TNF, IL, and interferon family members [3]. IL- $1 \beta$ and IFN- $\gamma$ are pro-inflammatory cytokines, while IL-4 is an anti-inflammatory cytokine, which are secreted by Th1 and Th2 respectively [4]. A proper balance of the cytokines is necessary to make intestine healthy [5]. TNBS could change the cytokines, such as TNF- $\alpha$, IFN- $\gamma$, IL- 4 and IL- $1 \beta$, and even some study take these cytokines as UC markers [6]. As residents with a large population living in the gastrointestinal tract, gut microbiota have much relationship with UC [7]. Studies revealed that some special gut microflora could lead to UC or make it worse. Bacteriodetes and Firmicutes are dominant in small intestine, whose total population account for more than $90 \%$ in all phylotypes [8]. The different ratio of Bacteriodetes and Firmicutes usually serves as the change of microbial structure [9]. Being the probiotics, Bifidobacteria and Lactobacillus could alleviate some disease by supplying with some nutrition, such as vitamin C and so on [10]. Clostridium leptum is a producer of butyrate, which contains large quantity of enzymes to make use of fiber and polysaccharide [11].

It is reported that Chinese herbal formula Yupingfeng powder have anti-colitis activity, which is consisted of Radix Astragali (Huang-Qi), Rhizoma Atractylodis Macrocephalae (Bai-Zhu), and Radix Saposhnikoviae (Fang-Feng) [12]. As a chinese herb, sea cucumber is also a kind of traditional food. Sea cucumbers belong to phylum Echinodermata and have many bioactive materials such as phospholipids, and A. japonicus is a very precious sea cucumber which is popular in Asia as luxury food. It revealed that $A$. japonicus could restore mice intestinal mucosal immunity after being immunosuppressive [13]. Some believe that Sea cucumbers are not suitable for the UC patients, and patients are not at a good digestive absorption condition, which will make the situation even worse. Xue et al. reported that the different processing method might change the ingredient of sea cucummber [14]. This study tried to explore and evaluated by gut microbiota and cytokines whether different processing methods of $A$. japonicus have a good effect on UC.

\section{Materials and Methods}

\subsection{Materials}

The fresh sea cucumbers $A$. japonicus were purchased from Nanshan markets in Qingdao. All the sea cucumbers were boiled for $10 \mathrm{~min}$, then three different processures were taken. To produce dried $A$. japonicus, the boiled sea cucumbers were placed into the cold air oven at $20^{\circ} \mathrm{C}$ for 6 days, then soaked in distilled water for 2 days and boiled for 30 minutes, and these were soaked again for 3 days at $4^{\circ} \mathrm{C}$ after cooled. Like instant $A$. japonicus, the sea cucumber were put into the condiments for 1 hour and sterilized at 
$121^{\circ} \mathrm{C}$ for 15 minutes. As enzymatic $A$. japonicus, the sea cucumber were dealed with papain at $50^{\circ} \mathrm{C}$ for 12 hours after treated like the instant one, then inactivated the papain at $100^{\circ} \mathrm{C}$ for 10 mins and centrifuged for supernatant. After those, they were stored in the refrigerator at $-40^{\circ} \mathrm{C}$. The sea cucumbers were crushed and dissolved in saline before given to the mice.

All the reagents used in the animal experiments were analytically pure.

\subsection{Animal Maintenance and Treatment}

Male balb/c mice (19 $\pm 1 \mathrm{~g}$, 4 weeks old) were obtained from Vital River (Beijing, China). During the experimental period, the mice were housed in a room maintained under a $12 \mathrm{~h} \mathrm{light/dark}$ cycle at $24^{\circ} \mathrm{C}$ and a relative humidity of $65 \% \pm 15 \%$. Mice had free access to standard laboratory pellet chow (Kangda, Jinan, China) and fresh water.

After one week adaption time, the mice were randomly assigned to five groups with 10 in each group following by normal, TNBS model and $A$. japonicus groups treated with three different processing methods. Except for the normal group, the others were treated with $0.2 \mathrm{~mL} 1.5 \%$ TNBS through enteroclysis from the beginning for once. The normal mice were taken saline instead as control. The $A$. japonicus groups were given $512 \mathrm{mg} \cdot \mathrm{kg}^{-1}$ [13] sea cucumbers by gavage for 10 days respectively, while the normal and model groups were given saline as control. The body weights of mice were recorded every two days. The feces were collected on the 10th day. Following overnight fasting, the mice were sacrificed by cervical dislocation on the 11th day after anaesthetized with diethyl ether and the small intestine was collected for analysis. All experimental procedures were conducted according to the guidelines provided by the ethical committee of experimental animal care at Ocean University of China (OUC, Qingdao, China).

\subsection{DNA Extraction}

Bacterial genomic DNA was extracted from the fecal samples with the QIAamp DNA stool kit (Qiagen, Germantown, MD), according to the manufacturer's instruction.

\subsection{Polymerase Chain Reaction and Denaturing Gradient Gel Electrophoresis Analysis}

Bacterial universal primers GC-338F (5'-CGCCCGGGGCGCGCCCCGGGGCGGGGCGGGGGCGC-GGGGGGCCTACGGGAGGCAGCAG-3') and 518R (5'-ATTACCGCGGCTGCTGG-3') were used to amplify the $16 \mathrm{~S}$ rDNA gene V3 region by PCR. The PCR amplification was carried out in a MJ Mini Personal Thermal Cycler (BIO-RAD, America). Each reaction was performed in a total volume of $50 \mu \mathrm{L}$ containing DNA template $100 \mathrm{ng}, 10 \times$ PCR buffer $5 \mu \mathrm{L}$, dNTP mix $(10 \mathrm{mM}) 3.2 \mu \mathrm{L}, \mathrm{MgCl}_{2}(25 \mathrm{mM}) 3$ $\mu \mathrm{L}$, each primer $(20 \mathrm{mM}) 0.5 \mu \mathrm{L}$, and $5 \mathrm{U} / \mu \mathrm{L}$ of Taq DNA polymerase (Takara, Japan) 1 $\mu \mathrm{L}$. The thermal cycler profile consisted of an initial denaturation step of $5 \mathrm{~min}$ at $94^{\circ} \mathrm{C}$ followed by $30 \mathrm{cycles}$ at $94^{\circ} \mathrm{C}$ for $30 \mathrm{~s}, 55^{\circ} \mathrm{C}$ for $30 \mathrm{~s}, 72^{\circ} \mathrm{C}$ for $30 \mathrm{~s}$, and a final extension at $72^{\circ} \mathrm{C}$ for $10 \mathrm{~min}$. DGGE was carried out with a Dcode System apparatus (Bio-Rad, 
Herts, UK) and a gradient from $35 \%$ - 55\% (7M urea and $40 \%$ deionized formamide were considered to be the $100 \%$ denaturant). The gel images were converted into digital data using Canoco. Principal component analysis (PCA) and cluster analysis were employed to compare the gut microbiota composition among groups. Important bands were retrieved, sequenced (Sangon Biotech Co. Ltd., Shanghai, China) and identified in Genbank, as described [15].

\subsection{Real-Time Quantitative Polymerase Chain Reaction}

Quantifications of Bacteroidetes, Firmicutes, Clostridium leptum, Bifidobacteria and Lactobacillus were assayed by quantitative real-time PCR. $25 \mu \mathrm{L}$ of the reaction volume was used for the quantitative real-time PCR assay that consisted of $12.5 \mu \mathrm{L}$ of Maxima SYBR Green qPCR Master Mix (Roche, Switzerland), $0.75 \mu \mathrm{L} 10 \mu \mathrm{M}$ of primers (each

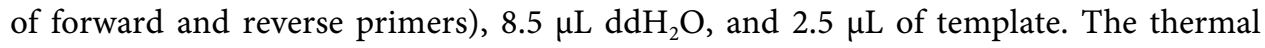
conditions consisted of an initial denaturation at $95^{\circ} \mathrm{C}$ for $10 \mathrm{~min}$ followed by 45 cycles of denaturation at $95^{\circ} \mathrm{C}$ for $15 \mathrm{~s}$, annealing at $60^{\circ} \mathrm{C}$ for $20 \mathrm{~s}$ and extension at $72^{\circ} \mathrm{C}$ for 30 s. The sequences of the primers used in this study are described in Table 1.

\subsection{Statistical Analysis}

A one-way analysis of variance between different groups were operated by SPSS V 18.0 software. Data were presented as mean \pm standard error and statistical significance was defined to be $p<0.05$.

\section{Results}

\subsection{Changes of Structure in the Gut Microbiota by Polymerase Chain Reaction and Denaturing Gradient Gel Electrophoresis (PCR-DGGE)}

The principal components analysis (PCA) of the fingerprints revealed that the mice groups were made into three clusters, with first principal component (PC1) accounting

Table 1. The 16S rRNA gene-targeted group-specific primers of bacteria.

\begin{tabular}{ccc}
\hline Specific groups & Primers name & Primer sequence \\
\hline \multirow{2}{*}{ Bacteroidetes } & Bfr-F & CTGAACCAGCCAAGTAGCG \\
& Bfr-R & CCGCAAACTTTCACAACTGACTTA \\
Firmicutes & Fir-F & GGAGYATGTGGTTTAATTCGAAGCA \\
& Fir-R & AGCTGACGACAACCATGCAC \\
Bifidobacteria & Bif-F & CCTACGGGAGGCAGCAG \\
& Bif-R & ATTACCGCGGCTGCTGG \\
Lactobacillus & Lac-F & AGCAGTAGGGAATCTTCCA \\
& Lac-R & ATTTCACCGCTACACATG \\
Clostridium leptum & Clept-F & GCACAAGCAGTGGAGT \\
& Clept-R & CTTCCTCCGTTTTGTCAA \\
\hline
\end{tabular}


for $49.7 \%$ of the vatriation (Figure 1(a)). The model and dried A. japonicus groups were one of clusers, the normal group was another cluster, while the instant and enzymatic $A$. japonicus groups belonged to the last one. It showed that TNBS could change the composition of gut microbiota, and the cluster dendrogram indicated the dried $A$. japonicus group was closer to normal group compared with model one (Figure 1(b)). These datas suggested that three kinds of $A$. japonicus had different effects on gut microbial imbalance induced by TNBS, and dried $A$. japonicus could keep the balance.

According to the $16 \mathrm{~S}$ rRNA V3 region PCR-DGGE patterns, the overall composition after the TNBS treatment revealed significance different from that of normal group (Figure 2(a)). The bands in the model group changed significantly and comparing with normal group, the intensity of some bands decreased. This result indicated that TNBS had changed the structure and diversity of gut microbita. The difference of gut flora between $A$. japonicus groups had no significance and the diversity index of microbiota showed that the diversity of model group increased (Table 2), but in the virtual figure (Figure 2(b)) of PCR-DGGE fingerprint dried A. japonicus was more similar to normal group than others.

\subsection{The Significant Different Bands in Denaturing Gradient Gel Electrophoresis (DGGE) Fingerprints}

In model group, intensities of band A1, bandA2, bandA4, bandA6, bandA8, bandA9, bandA10 were significantly reduced. By sequence analysis, they were belonging to Clostridiales bacterium CIEAF 019 (99\% homology), Akkermansia muciniphila (99\%), Barnesiella sp. EBA4-14 (99\%), Barnesiella intestinihominis (99\%), Anaerostipes hadrus (99\%), Gram-negative bacterium cL10-2b-4 (90\%), Porphyromonadaceae bacterium
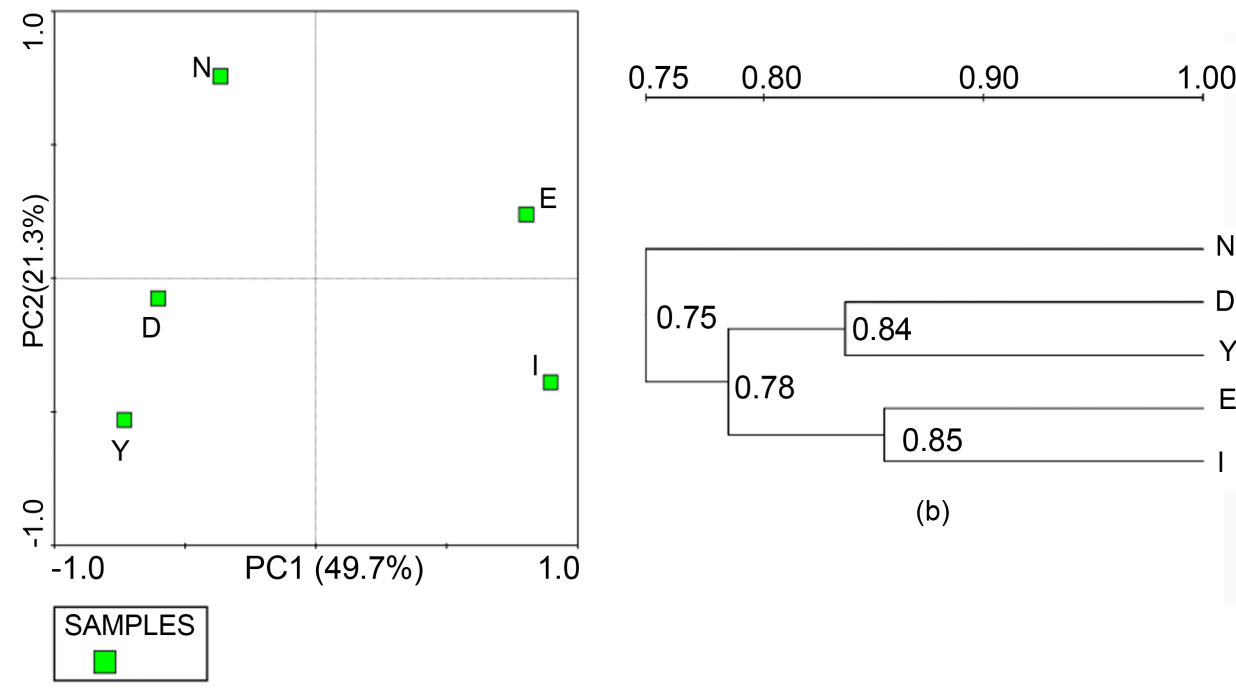

(b)

Figure 1. PCA and cluster analysis of DGGE fingerprint. (a) The principal components analysis (PCA) scores plot according to the DGGE fingerprint; (b) Clustering of gut microbiota based on distances between different groups. $\mathrm{N}$ serves as normal group and $\mathrm{Y}, \mathrm{D}, \mathrm{J}, \mathrm{E}$ represent model, dried, instant and enzymatic groups, respectively. 


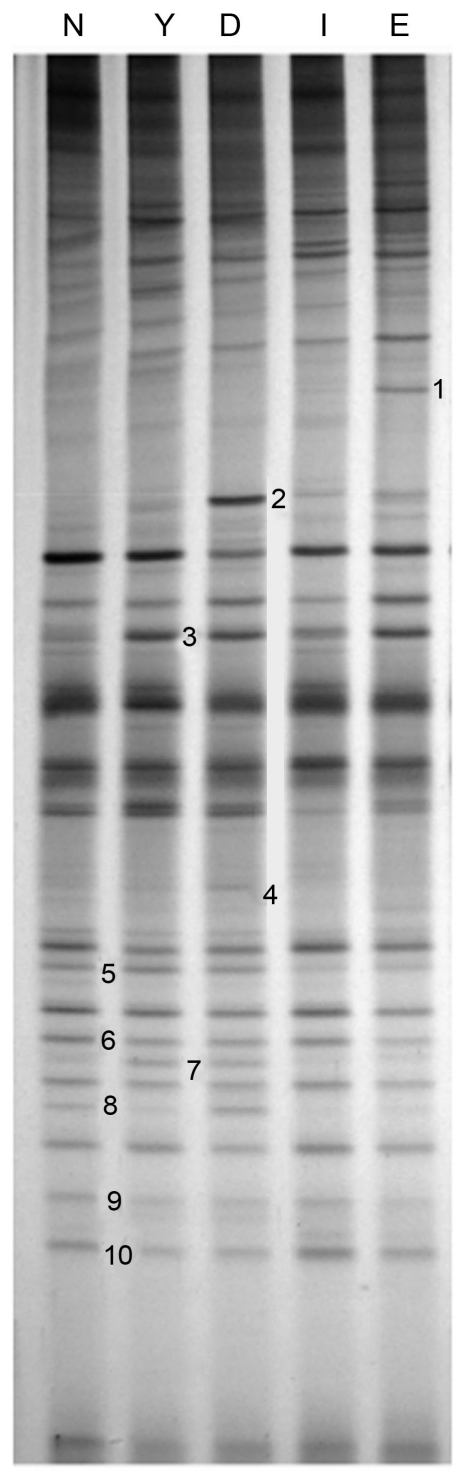

(a)

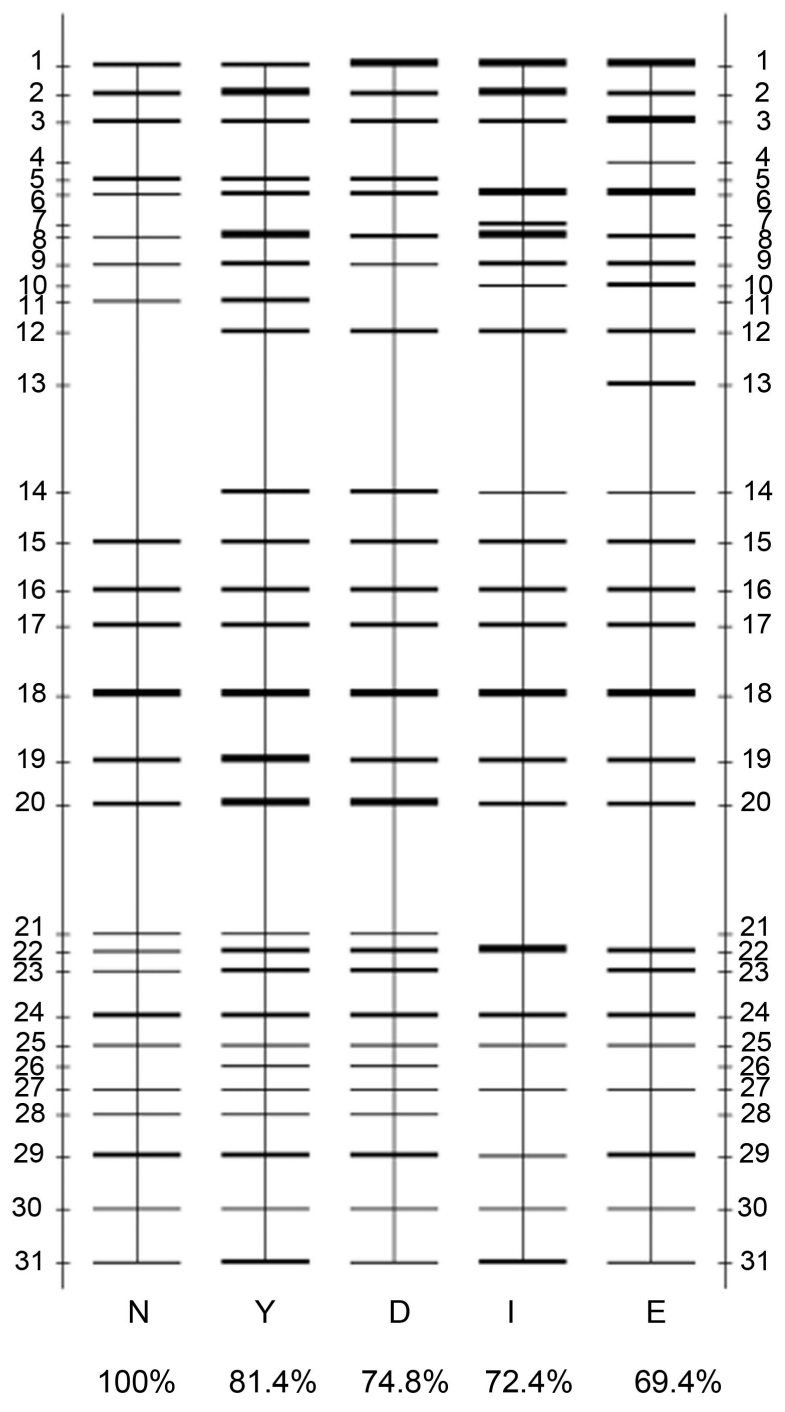

(b)

Figure 2. The difference of microbiota composition in the mouse groups. (a) Denaturing gradient gel electrophoresis (DGGE) fingerprinting of V3 region of $16 \mathrm{~S}$ rRNA genes from faecal bacterial communities; (b) The virtual map of DGGE electrophoresis. Each sample included feces of ten mice. $\mathrm{N}$ is for normal group and $\mathrm{Y}, \mathrm{D}, \mathrm{J}$, E represent model, dried, instant and enzymatic groups, respectively.

Table 2. Analysis of the microbiota diversity of mice intestine.

\begin{tabular}{cccc}
\hline Groups & Shannon-Wiener Index $(H)$ & Evenness $(E)$ & Richness $(S)$ \\
\hline N & 2.979 & 0.925 & 24 \\
Y & 3.052 & 0.916 & 27 \\
D & 3.044 & 0.924 & 26 \\
I & 2.977 & 0.937 & 23 \\
E & 3.057 & 0.938 & 25 \\
\hline
\end{tabular}


C941 (92\%) (Figure 4(a) and Table 3). BandA4, A6, A10 were involved in Porphyromonadaceae as well as other two bands A5 and A7. Studies revealed that Porphyromonadaceae were related to some diseases. Band A1, A2, A8, A9 were in Clostridia, Verrucomicrobiaceae, Lachnospiraceae and unknown bacteria respectively. Most of Clostridia could digest polysaccharide and protein, which is important for the absorption of nutrition. Verrucomicrobiaceae increased significantly in the dried group and Verrucomicrobiaceae was involved in producing butyrate which had a good effect on colon.

\subsection{Quantity Changes of Normal Bacteria Revealed by Real-Time Quantitative Polymerase Chain Reaction (RT-PCR)}

The quantity of Bacteriodetes, Firmicutes, Clostridium leptum, Bifidobacteria and Lactobacillus were detected by real time-PCR. Data revealed that the ratio of Bacteriodetes and Firmicutes decreased after treatment of TNBS in model group (Figure 3(a)). A. japonicus could help increase the ratio significantly in the instant group. The quantity of Clostridium leptum decreased significantly $(p<0.01)$ in model group, while it increased in dried group (Figure 3(b)). Both Bifidobacteria and Lactobacillus decreased significantly in the model group caused by TNBS (Figure 3(c) and Figure 3(d)). A. japonicus could improve the quantity of Bifidobacteria and Lactobacillus but with no

Table 3. The analysis results of DGGE gel bands recovery sequence.

\begin{tabular}{|c|c|c|c|c|}
\hline $\begin{array}{c}\text { Band } \\
\text { Number }\end{array}$ & Similar strain & $\begin{array}{l}\text { Accession } \\
\text { number }\end{array}$ & Similarity & Classification \\
\hline BandA1 & Clostridiales bacterium CIEAF 019 & AB702936 & 99 & $\begin{array}{l}\text { Clostridia; } \\
\text { Clostridiales }\end{array}$ \\
\hline BandA2 & Akkermansia muciniphila & NR_074436 & 99 & $\begin{array}{c}\text { Verrucomicrobiaceae } \\
\text { Akkermansia }\end{array}$ \\
\hline BandA3 & Lactobacillus reuteri & EF412975 & 99 & $\begin{array}{l}\text { Lactobacillaceae, } \\
\text { Lactobacillus }\end{array}$ \\
\hline BandA4 & Barnesiella sp. EBA4-14 & EF608208 & 99 & $\begin{array}{c}\text { Porphyromonadaceae } \\
\text { Barnesiella }\end{array}$ \\
\hline BandA5 & $\begin{array}{c}\text { Porphyromonadaceae bacterium } S 9 \\
H S-8\end{array}$ & KF007168 & 91 & $\begin{array}{c}\text { Porphyromonadaceae } \\
\text { unclassified } \\
\text { Porphyromonadaceae }\end{array}$ \\
\hline BandA6 & Barnesiella intestinihominis & NR_113073 & 99 & $\begin{array}{c}\text { Porphyromonadaceae } \\
\text { Barnesiella }\end{array}$ \\
\hline BandA7 & Barnesiella sp. 177 & KJ572412 & 90 & $\begin{array}{c}\text { Porphyromonadaceae } \\
\text { Barnesiella }\end{array}$ \\
\hline BandA8 & Anaerostipes hadrus & NR_104799 & 99 & $\begin{array}{l}\text { Lachnospiraceae; } \\
\text { Anaerostipes. }\end{array}$ \\
\hline BandA9 & Gram-negative bacterium $c L 10-2 b-4$ & AY239469 & 90 & Bacteria \\
\hline BandA10 & $\begin{array}{l}\text { Porphyromonadaceae bacterium } \\
\text { C941 }\end{array}$ & JF803519 & 92 & $\begin{array}{c}\text { Porphyromonadaceae } \\
\text { unclassified } \\
\text { Porphyromonadaceae }\end{array}$ \\
\hline
\end{tabular}

Ten important bands were cut from the gel, sequenced and then identified in Genbank. 


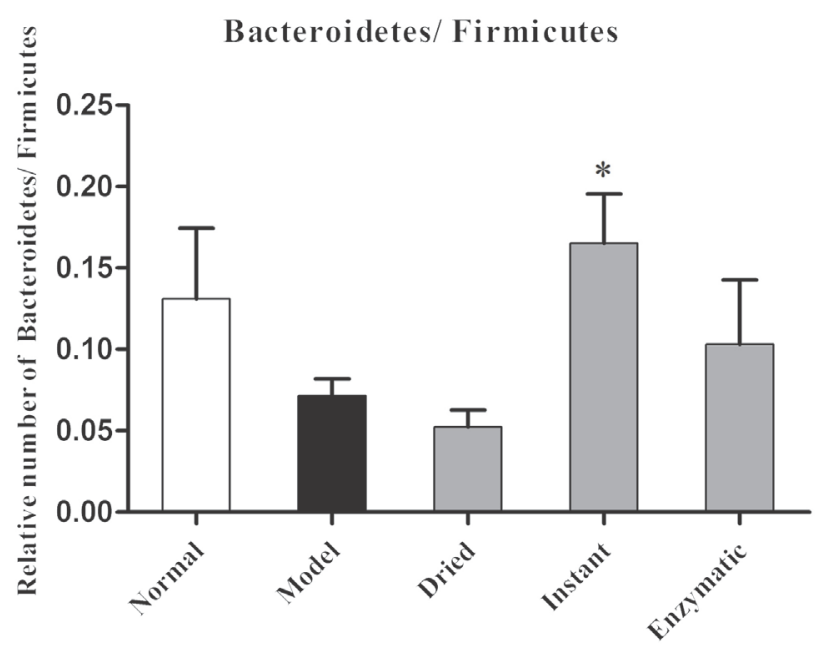

(a)

Bifidobacterium

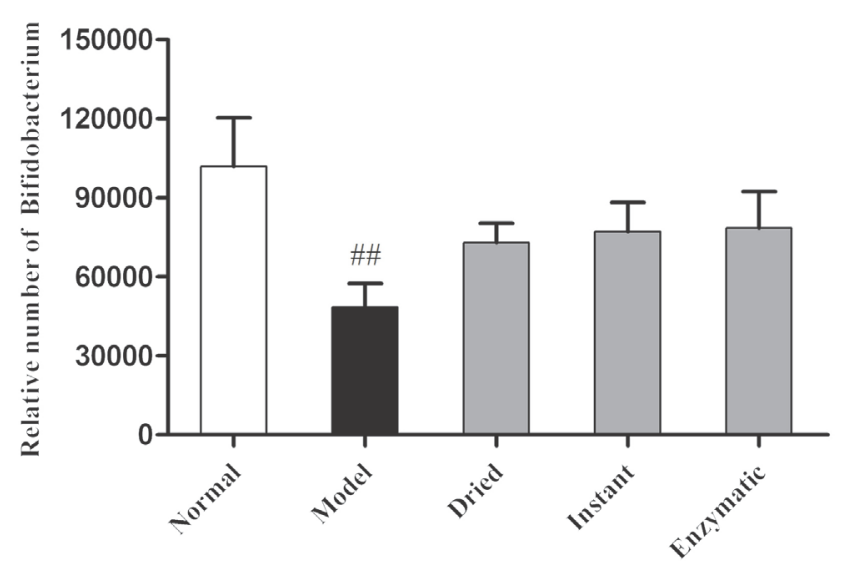

(c)

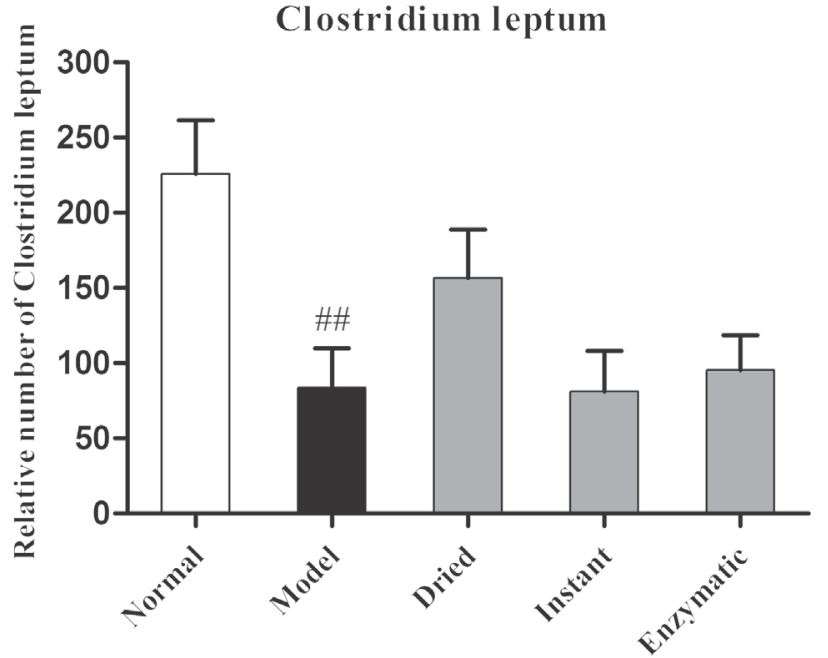

(b)

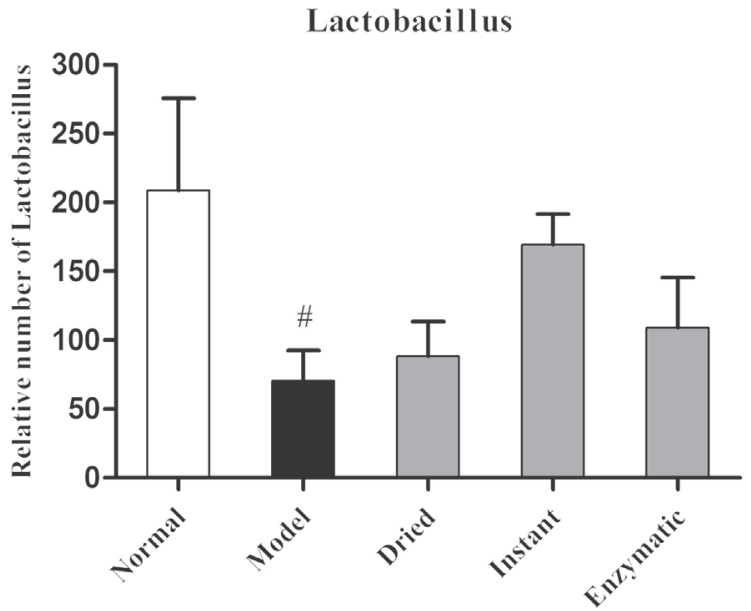

(d)

Figure 3. The quantity of gut microflora analysised by real time-PCR in different groups. (a) Bacteriodetes and Firmicutes; (b) Clostridlum leptu; (c) Bifidobacteria; and (d) Lactobacillus. Values are expressed as mean \pm S.E.M. "Significantly different from normal group, $p<$ $0.05 ;{ }^{\star}$ Significantly different from model group, $p<0.05$.

significance. The data indicated that $A$. japonicus administration could help against the damage of TNBS by increasing the quantity of Clostridium leptum, Bifidobacteria and Lactobacillus.

\subsection{A. japonicus Inhibit the Upregulated Pro-Inflammatory Cytokines of Ulcerative Colitis Mice}

The results indicated that $A$. japonicus reduced the mRNA expression of IL-1 $\beta$, while it increased significantly $(p<0.05)$ in model group (Figure 4(a)). Compared with normal group, the expression of IFN- $\gamma / \mathrm{IL}-4$ also upregulated notably (Figure 4(b)). Dried and instant $A$. japonicus improved the expression of IFN- $\gamma / \mathrm{IL}-4$, and the dried group had significant effects $(p<0.01)$. Three types of $A$. japonicus could decrease the expression of IL- $1 \beta$, but only dried and enzymatic groups showed statistical significance $(p<0.05)$. 


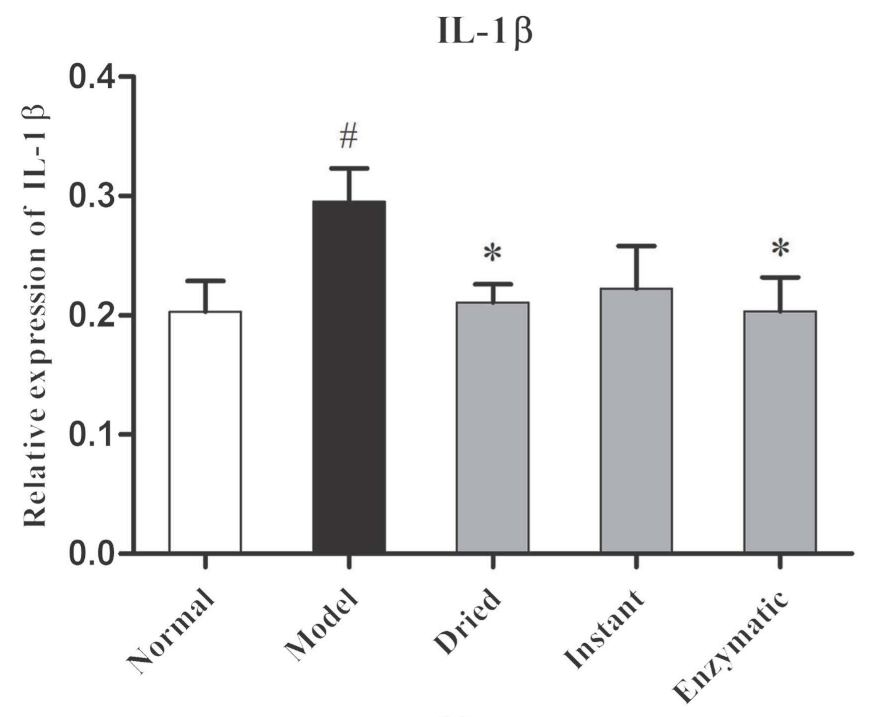

(a)

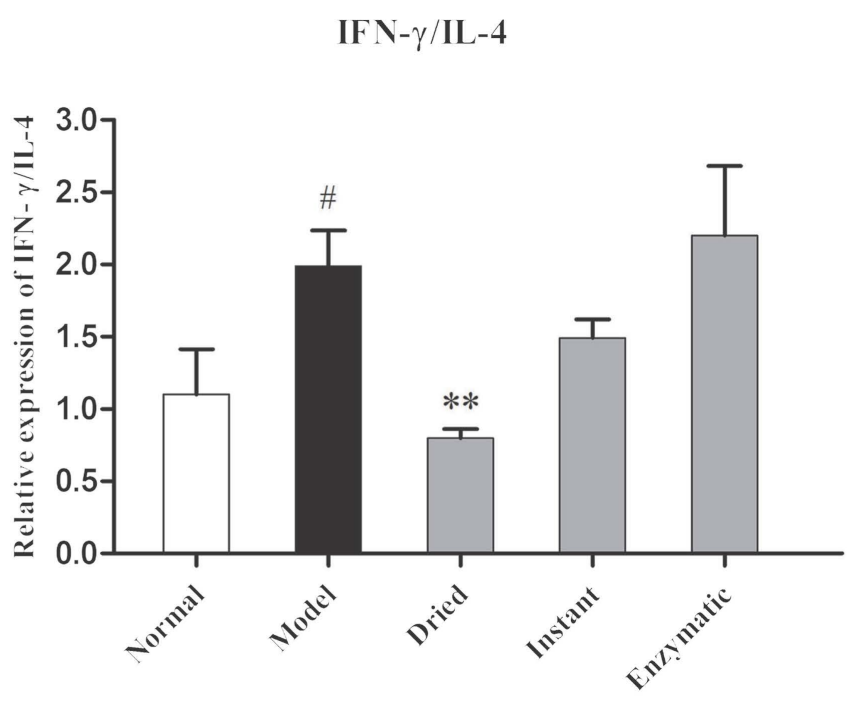

(b)

Figure 4. Relative expression of IL-4, IFN- $\gamma$ and IL- $1 \beta$ in small intestine. IL-4, IFN- $\gamma$ and IL- $1 \beta$ relative expression were analyzed by RT-PCR. Each value represents Mean \pm S.E.M of 10 mice in each group. ${ }^{\#}$ Significantly different from normal group, $p<0.05 ;{ }^{\star}$ Significantly different from model group, $p<0.05$; ${ }^{\star \star}$ Significantly different from model group, $p<0.01$.

These data implied that $A$. japonicus might alleviate the ulcerative colitis induced by TNBS in mice.

\section{Discussion}

TNBS is a common drug to induce ulcerative colitis [16]. It could destroy mucosa of small intestine, which is an important barrier for organism. IFN- $\gamma$, IL-4 and IL- $1 \beta$ are cytokines which play great role in the health of the intestine, while IL-4 is an anti-inflammatory cytokine and IFN- $\gamma$ and IL- $1 \beta$ are pro-inflammatory cytokines. However they all play important roles in maintaining intestinal mucosa. Seriously, that change leads to produce more pro-inflammation cytokines making much more suffering and be much easier for the bacteria to translocate into the inner gut [17] [18]. In this study, the expression of IFN- $\gamma /$ IL- 4 and IL- $1 \beta$ increased significantly in the model group, and that was consistent with the reports [19] [20]. A. japonicus could decrease the expression of IFN- $\gamma /$ IL- 4 and IL- $1 \beta$, and only dried showed significance in both IFN- $\gamma /$ IL- 4 and IL- $1 \beta$ among the three different processing methods. Bacteriodetes and Firmicutes are predominent in gut microflora. The change of ratio between Bacteriodetes and Firmicutes reflects different structures of intestinal microbiota. The mojority species of Clostridium leptum are the producers of butyrate which is the major and important energy of intestinal epithelial cells of colon. Some bacteria are good for the body, such as Bifidobacteria and Lactobacillus, and they can provide some nutritions by fermentating fiber or hydrlyzing protein and fat acid. The results of PCR-DGGE and RT-PCR indicated that cyclophosphamide broke the balance of gut microbiota, including reducing microbial diversity and composition, and abundance of the ratio between Bacteriodetes and Firmicutes, Clostridium leptum, Bifidobacterium and Lactobacillus. 
$A$. japonicus could reverse all of these changes. The instant and enzymatic could increase the ratio of Bacteriodetes and Firmicutes, while the three methods all could improve the abundance of Clostridlum leptu, Bifidobacteria and Lactobacillus. The instant had the best effect on regulating the Bacteriodetes/Firmicutes and Lactobacillus, with the dried regulating Clostridium leptum, but they all got no difference on the Bifidobacteria.

As a big family living in the gut, intestinal flora have much effect on the health [21]-[23]. So we drew attention to the intestinal microflora. The gastrointestinal tract in an adult human being has been measured to contain approximately 500 to 1000 distinct bacterial species [24]. Their DNA is more than 10 times of an adult, and this give them an ability to synsthesize many kinds of enzymes, some of which even don't exist in mammals. That made them more capable to help hydrolyze and absorb some complex component, especially for fermentation polysaccharide to acquire short chain fat acid (SCFA) [25]-[28]. Meanwhile microbiota or butyrate produced by commensal microorganisms was associated with the balance between pro- and anti-inflammatory mechanisms [29]-[31]. The DGGE electrophoresis revealed that there was no remarkable difference between the normal and model group, and it might predict that we didn't give enough amount of TNBS. However, in analysis of microbiota diversity, PCA and cluster, we got the difference among the group and the dried had more similarity with normal group compared with other groups. The variation of Clostridlum leptu in dried was much better than other two groups. Therefore, dried $A$. japonicus had the best effect on modulating the intestinal microbiota. This study might help UC patients to choose the right products of sea cucumbers.

Xue et al. reported that the different processing method might change the ingredient of sea cucummber [14]. Therefore, we checked the protein and polysaccharide in the three types of $A$. japonicus. The result indicated that the protein of dried, instant and enzymatic $A$. japonicus was $73.09 \%, 65.06 \%, 57.42 \%$, and polysaccharide was $6.72 \%$, $5.46 \%, 5.45 \%$ respectively. Although the mechanism needs to be explored deeply, our present study confirmed that the different component of three $A$. japonicus might have influence on gut microflora, which could contributed to different effects on UC. Collectively, Our study have revealed that dried $A$. Japonicus have better effect on UC, but we still didn't know which component in A. Japonicus works on UC. In the future study, we need to figure out the effective component and how the component interact with intestinal microbial species, if the production of SCFA deprived by microbiota have an effcet on UC.

\section{Conclusion}

$A$. japonicus could decrease the expression of IFN- $\gamma /$ IL- 4 and IL- $1 \beta$, and regulate intestinal microbiota to alleviate mice ulcerative colitis caused by TNBS. The processing methods indeed have an effect on the content of sea cucumber nutritions, especially for modulation of gut microflora. This study might provide a new method for $A$. japonicus to reduce the pain of UC patients. 


\section{Acknowledgements}

This work was supported by the National Natural Science Foundation of China (grant number: 31330060), and Special funds for the Taishan Scholar construction project.

\section{References}

[1] Ordás, I., Eckmann, L., Talamini, M., et al. (2011) Ulcerative Colitis. Lancet, 380, 16061619. http://dx.doi.org/10.1016/S0140-6736(12)60150-0

[2] Qiu, W., Wu, B., Wang, X., et al. (2011) PUM, A-Mediated Intestinal Epithelial Apoptosis Contributes to Ulcerative Colitis in Humans and Mice. Journal of Clinical Investigation, 121, 1722-1732. http://dx.doi.org/10.1172/JCI42917

[3] Singh, U.P., Singh, N.P., Murphy, E.A., et al. (2015) Chemokine and Cytokine Levels in Inflammatory Bowel Disease Patients. Cytokine, 77, 44-49.

http://dx.doi.org/10.1016/j.cyto.2015.10.008

[4] Zhang, M., et al. (2006) Curcumin Regulated Shift from Th1 to Th2 in Trinitrobenzene Sulphonic-Induced Chronic Colitis. Acta Pharmacologica Sinica, 27, 1071-1077. http://dx.doi.org/10.1111/j.1745-7254.2006.00322.x

[5] Lv, Q., Qiao, S.M., Xia, Y., et al. (2015) Norisoboldine Ameliorates DSS-Induced Ulcerative Colitis in Mice through Induction of Regulatory T Cells in Colons. International Immunopharmacology, 29, 787-797. http://dx.doi.org/10.1016/j.intimp.2015.08.040

[6] Bai, A.P., Lu, N.H., Zeng, H., et al. (2010) All-Trans Retinoic Acid Ameliorates Trinitrobenzene Sulfonic Acid-Induced Colitis by Shifting Th1 to Th2 Profile. Journal of Interferon \& Cytokine Research, 30, 399-406. http://dx.doi.org/10.1089/jir.2009.0028

[7] Uronis, J.M., Arthur, J.C., Temitope, K., et al. (2011) Gut microbial Diversity Is Reduced by the Probiotic VSL\#3 and Correlates with Decreased TNBS-Induced Colitis. Inflammatory Bowel Diseases, 17, 289-297. http://dx.doi.org/10.1002/ibd.21366

[8] Rosa, K.B., Zehra, E.I., et al. (2012) Effects of Gut Microbes on Nutrient Absorption and Energy Regulation. Nutrition in Clinical Practice, 27, 201-214. http://dx.doi.org/10.1177/0884533611436116

[9] Morgan, X.C., Tickle, T.L., Sokol, H., et al. (2012) Dysfunction of the Intestinal Microbiome in Inflammatory Bowel Disease and Treatment. Genome Biology, 13, 1-18. http://dx.doi.org/10.1186/gb-2012-13-9-r79

[10] Wang, W., Chen, L.P., Zhou, R., et al. (2014) Increased Proportions of Bifidobacterium and the Lactobacillus Group and Loss of Butyrate-Producing Bacteria in Inflammatory Bowel Disease. Journal of Clinical Microbiology, 52, 398-406. http://dx.doi.org/10.1128/JCM.01500-13

[11] Kabeerdoss, J., Sankaran, V., et al. (2013) Clostridium leptum Group Bacteria Abundance and Diversity in the Fecal Microbiota of Patients with Inflammatory Bowel Disease: A CaseControl Study in India. BMC Gastroenterology, 13, 1-8. http://dx.doi.org/10.1186/1471-230X-13-20

[12] Zang, K.H., Rao, Z., et al. (2015) Anticolitis Activity of Chinese Herbal Formula Yupingfeng Powder via Regulating Colonic Enterochromaffin Cells and Serotonin. Indian Journal of Pharmacology, 47, 632-637. http://dx.doi.org/10.4103/0253-7613.169584

[13] Zheng, R., Li, X.M., Cao, B.B., et al. (2014) Dietary Apostichopus Japonicus Enhances the Respiratory and Intestinal Mucosal Immunity in Immunosuppressive Mice. Bioscience Biotechnology \& Biochemistry, 79, 253-259. http://dx.doi.org/10.1080/09168451.2014.955454 
[14] Xue, C.H., Xue, Y., Wang, J.F., et al. (2007) Sea Cucumber Nutrient and Its Preparing Process. 2007 CN 101016506 A.

[15] Otsuka, M., Kang, Y.J., Ren, J.L., et al. (2010) Distinct Effects of P38 $\alpha$ Deletion in Myeloid Lineage and Gut Epithelia in Mouse Models of Inflammatory Bowel Disease. Gastroenterology, 138, 1255-1265. http://dx.doi.org/10.1053/j.gastro.2010.01.005

[16] Zhou, W., Cao, Q., Peng, Y., et al. (2009) FoxO4 Inhibits NF- $\kappa$ B and Protects Mice against Colonic Injury and Inflammation-Gastroenterology. Gastroenterology, 137, 1403-1414. http://dx.doi.org/10.1053/j.gastro.2009.06.049

[17] Aline, W., Luchini, A.C., Hiruma-Lima, C.A., et al. (2012) Suppression of TNBS-Induced Colitis in Rats by 4-Methylesculetin, a Natural Coumarin: Comparison with Prednisolone and Sulphasalazine. Chemico-Biological Interactions, 195, 76-85. http://dx.doi.org/10.1016/j.cbi.2011.11.004

[18] Brian, C., Violeta, Z., et al. (2015) Effect of Genetic Deletion or Pharmacological Antagonism of Tumor Necrosis Factor Alpha on Colitis-Associated Carcinogenesis in Mice. Inflammatory Bowel Diseases, 21, 485-495. http://dx.doi.org/10.1097/MIB.0000000000000303

[19] Inagaki-Ohara, K., Sasaki, A., Matsuzaki, G., et al. (2006) Suppressor of Cytokine Signalling 1 in Lymphocytes Regulates the Development of Intestinal Inflammation in Mice. Gut, 55, 212-219. http://dx.doi.org/10.1136/gut.2004.062653

[20] Pender, S.L., Chance, V., Whiting, C.V., et al. (2005) Systemic Administration of the Chemokine Macrophage Inflammatory Protein $1 \alpha$ Exacerbates Inflammatory Bowel Disease in a Mouse Model. Gut, 54, 1114-1120. http://dx.doi.org/10.1136/gut.2004.052779

[21] Doré, J. and Blottière, H. (2015) The Influence of Diet on the Gut Microbiota and Its Consequences for Health. Current Opinion in Biotechnology, 32, 195-199. http://dx.doi.org/10.1016/j.copbio.2015.01.002

[22] Tuohy, K.M., Hinton, D.J.S., Davies, S.J., et al. (2006) Metabolism of Maillard Reaction Products by the Human Gut Microbiota Implications for Health. Molecular Nutrition \& Food Research, 50, 847-857. http://dx.doi.org/10.1002/mnfr.200500126

[23] Tojo, R., Suárez, A., Clemente, M.G., et al. (2014) Intestinal Microbiota in Health and Disease: Role of Bifidobacteria in Gut Homeostasis. World Journal of Gastroenterology, 20, 15163-15176. http://dx.doi.org/10.3748/wjg.v20.i41.15163

[24] Eckburg, P.B., Bik, E.M., Bernstein, C.N., et al. (2005) Diversity of the Human Intestinal Microbial Flora. Science, 308, 1635-1638. http://dx.doi.org/10.1126/science.1110591

[25] Wichmann, A., Allahyar, A., Greiner, T.U., et al. (2013) Microbial Modulation of enerGy Availability in the Colon Regulates Intestinal Transit. Cell Host \& Microbe, 14, 582-590. http://dx.doi.org/10.1016/j.chom.2013.09.012

[26] Hamer, H.M., Jonkers, D., et al. (2008) The Role of Butyrate on Colonic Function. Alimentary Pharmacology \& Therapeutics, 27, 104-119. http://dx.doi.org/10.1111/j.1365-2036.2007.03562.x

[27] Tremaroli, V. and Bäckhed, F. (2012) Functional Interactions between the Gut Microbiota and Host metabolism. Nature, 489, 242-249. http://dx.doi.org/10.1038/nature11552

[28] Mariadason, J.M., Catto-Smith, A. and Gibson, P.R. (1999) Modulation of Distal Colonic Epithelial Barrier Function by Dietary Fibre in Normal Rats. Gut, 44, 394-399. http://dx.doi.org/10.1136/gut.44.3.394

[29] Josefowicz, S.Z., Niec, R.E., Hye Young, K., et al. (2012) Extrathymically Generated Regulatory T Cells Control Mucosal Th2 Inflammation. Nature, 482, 395-399. http://dx.doi.org/10.1038/nature10772

[30] Nicholas, A., Clarissa, C., Xiying, F., et al. (2013) Metabolites Produced by Commensal 
Bacteria Promote Peripheral Regulatory T Cell Generation. Nature, 504, 451-455.

http://dx.doi.org/10.1038/nature12726

[31] Honda, K. and Littman, D.R. (2012) The Microbiome in Infectious Disease and Inflammation. Annual Review of Immunology, 30, 759-795.

http://dx.doi.org/10.1146/annurev-immunol-020711-074937

Submit or recommend next manuscript to SCIRP and we will provide best service for you:

Accepting pre-submission inquiries through Email, Facebook, LinkedIn, Twitter, etc. A wide selection of journals (inclusive of 9 subjects, more than 200 journals)

Providing 24-hour high-quality service

User-friendly online submission system

Fair and swift peer-review system

Efficient typesetting and proofreading procedure

Display of the result of downloads and visits, as well as the number of cited articles

Maximum dissemination of your research work

Submit your manuscript at: http://papersubmission.scirp.org/

Or contact jbm@scirp.org 